Article

\title{
Investigation of the Formation of Coherent Ash Residues during Fluidized Bed Gasification of Wheat Straw Lignin
}

\author{
Juraj Priscak ${ }^{1,2, *(\mathbb{D})}$, Katharina Fürsatz ${ }^{1,2}$, Matthias Kuba ${ }^{1,2}$, Nils Skoglund ${ }^{1,2,3}$, \\ Florian Benedikt ${ }^{2}$ and Hermann Hofbauer ${ }^{2}$ (D) \\ 1 BEST-Bioenergy and Sustainable Technologies GmbH, Inffeldgasse 21b, A-8010 Graz, Austria; \\ katharina.fuersatz@best-research.eu (K.F.); matthias.kuba@best-research.eu (M.K.); \\ nils.skoglund@umu.se (N.S.) \\ 2 Institute of Chemical, Environmental and Bioscience Engineering (ICEBE), Technische Universität Wien, \\ Getreidemarkt 9/166, 1060 Vienna, Austria; florian.benedikt@tuwien.ac.at (F.B.); \\ hermann.hofbauer@tuwien.ac.at (H.H.) \\ 3 Thermochemical Energy Conversion Laboratory, Umeå University, 90187 Umeå, Sweden \\ * Correspondence: juraj.priscak@best-research.eu
}

Received: 30 June 2020; Accepted: 30 July 2020; Published: 1 August 2020

\begin{abstract}
Thermal conversion of ash-rich fuels in fluidized bed systems is often associated with extensive operation problems caused by the high amount of reactive inorganics. This paper investigates the behavior of wheat straw lignin - a potential renewable fuel for dual fluidized bed gasification. The formation of coherent ash residues and its impact on the operation performance has been investigated and was supported by thermochemical equilibrium calculations in FactSage 7.3. The formation of those ash residues, and their subsequent accumulation on the surface of the fluidized bed, causes temperature and pressure fluctuations, which negatively influence the steady-state operation of the fluidized bed process. This paper presents a detailed characterization of the coherent ash residues, which consists mostly of silica and partially molten alkali silicates. Furthermore, the paper gives insights into the formation of these ash residues, dependent on the fuel pretreatment (pelletizing) of the wheat straw lignin, which increases their stability compared to the utilization of non-pelletized fuel.
\end{abstract}

Keywords: fluidized bed conversion; combustion; gasification; wheat straw lignin; ash formation

\section{Introduction}

As at 2015 in Paris, at the 21st session of the Conference of the Parties (COP21), 195 countries had signed the Paris agreement, which aims to keep a global temperature rise at the end of the century below $2{ }^{\circ} \mathrm{C}$ compared to the pre-industrial levels. However, the new report from Intergovernmental Panel on Climate Change (October 2018, Korea) states that even with current policies, we are possibly on a pathway to increase the average global temperature by $3^{\circ} \mathrm{C}$ [1]. The increase of global temperature is directly linked to the release and concentrating of $\mathrm{CO}_{2}$ and other greenhouse gases in the atmosphere. Fossil fuels used in combustion are one major producer of greenhouse gases. Replacing fossil fuels with renewable resources, such as biomass, has, therefore, gained growing interest in the last years.

A wide array of different processes can be applied in order to convert biomass into useful forms of energy. The most widespread technology used today using biomass is combustion, which converts the chemical energy stored in biomass into heat and possibly electricity. Another thermochemical conversion process, gasification, offers the possibility to convert biomass into a gaseous secondary energy carrier-product gas, with high calorific value and nearly free of nitrogen. Moreover, the 
product gas can be further converted into biofuels or chemicals, and therefore can partially replace fossil fuels in chemical synthesis. Among the technologies available for biomass conversion, fluidized beds offer a number of advantages, such as providing uniform temperature and enhanced heat and mass transfer inside the reactor [2]. Another major advantage of this technology is its flexibility towards different types of biomass. General categories of biomass resources include forest-derived biomass, agricultural (energy) crops and wastes [3]. Especially agricultural wastes have gained increasing attention in recent years, since their stocking price is considerably lower compared to forest-derived biomass and energy crops.

However, the ash-forming matter in agricultural wastes is different in comparison to woody biomass and causes severe problems in operation, such as deposit build-up [4], slagging and bed agglomeration [5-9]. The latter is particularly important, since bed agglomeration may lead to total bed defluidization and as a consequence, termination of operation. Brus et al. highlighted two dominant agglomeration mechanisms in the field of biomass combustion and gasification: a melt- and a coating-induced mechanism [10]. Both types of bed agglomeration are caused to a large extent by low-melting alkali silicates. In the case of melt-induced agglomeration, the bed particles are glued together with molten ash, whereas the coating-induced agglomeration is preceded by formation of an alkali-silicate-dominated ash layer on the particle surface. Upon temperature increase, the ash layer melts, increasing its stickiness for other particles, and forms necks between bed material particles [11-14].

The formation of low-melting silicates is a result of transformation reactions between $\mathrm{Si}$ and other ash-forming elements such as $\mathrm{Ca}, \mathrm{Mg}, \mathrm{K}, \mathrm{Na}, \mathrm{P}, \mathrm{S}, \mathrm{Cl}$, Al and O [6]. According to Boström et al. [15], $\mathrm{Ca}, \mathrm{Mg}$ and $\mathrm{Si}\left(\mathrm{CaO}, \mathrm{MgO}\right.$ and $\mathrm{SiO}_{2}$ accordingly) show high chemical stability at typical combustion temperatures and will stay in the solid state throughout the thermodynamic conversion of biomass. $\mathrm{P}$ is available in the form of various phosphates and is probably released during the combustion process in the form of $\mathrm{P}_{2} \mathrm{O}_{5}(\mathrm{~g})$. $\mathrm{K}$ can be present in biomass either in the form of inorganic salts (e.g., $\mathrm{KCl}$ ), minerals (e.g., $\mathrm{K}_{2} \mathrm{O}_{3} \mathrm{Si}$ ) or can be organically bound to the carbon matrix (e.g., R-COO $\mathrm{K}^{+}$). Upon heating (above $\left.700{ }^{\circ} \mathrm{C}\right), \mathrm{K}$ is released into the gas phase as $\mathrm{KCl}(\mathrm{g}), \mathrm{KOH}(\mathrm{g})$ or $\mathrm{K}(\mathrm{g})$, depending on the chlorine and moisture content in the biomass [16,17]. S, which is present in plants mostly in reduced form $\left(\mathrm{S}^{2-}\right)$, has a lower affinity towards oxygen than towards the carbon-hydrogen matrix. Consequently, it will be released in elemental gaseous form as $\mathrm{S}_{2}(\mathrm{~g})$ or $\mathrm{H}_{2} \mathrm{~S}(\mathrm{~g})$ and form $\mathrm{SO}_{2}(\mathrm{~g})$ in further reactions with $\mathrm{O}_{2}[15,18]$. In secondary ash transformation reactions, the positively charged ions, like $\mathrm{K}^{+}, \mathrm{Na}^{+}, \mathrm{Ca}^{2+}, \mathrm{Mg}^{2+}, \mathrm{Al}^{3+}$ and $\mathrm{Fe}^{2+/ 3+}$, react with a negatively charged oxygen ion, $\mathrm{O}^{2-}$ $\left(\right.$ or $\mathrm{OH}^{-}$), as an electron acceptor (Lewis acid). The negatively charged ions (e.g., $\mathrm{SiO}_{3}{ }^{2-}, \mathrm{PO}_{3}{ }^{-}$) from the secondary reaction can react further in tertiary reactions either as an acid or a base. Especially important are reactions between silicates and alkali species in the biomass ash transformation chemistry. Du et al. [19] studied the transformation of inorganic crystalline structures upon heating from the ashes of wheat straw, rice straw, corn stalk and poplar using X-ray diffraction (XRD) analysis. They observed that at $600{ }^{\circ} \mathrm{C}, \mathrm{K}$ is present mainly in the form of $\mathrm{KCl}$. At higher temperatures, $\mathrm{K}$ is either released into the gas phase or reacts further with other inorganic species, forming compounds such as $\mathrm{KAlSiO}_{4}, \mathrm{~K}_{2} \mathrm{Ca}_{2}\left(\mathrm{SO}_{4}\right)_{3}$ and $\mathrm{KAlSi}_{3} \mathrm{O}_{8}$. These alkali silicates are prone to melt at elevated temperatures and may cause severe problems during plant operation [6,15].

Therefore, the investigation of the ash behavior during combustion and gasification in fluidized bed reactors is necessary prior to the implementation of a potential low-quality biomass resource in an industrial plant. One of the potential biomass resources, wheat straw lignin, has been investigated in the presented paper. Wheat straw lignin is obtained as a residue in a process, which converts wheat straw into bioethanol. In the process, lignin is separated from lignocellulosic biomass (in this case wheat straw) in a pretreatment process. Cellulose and hemicellulos-the other two biomass components, are hydrolyzed into simpler sugars in the next step and further converted into bioethanol [20]. Typically, lignin accounts for 15-20 wt.\%, hemicellulose for 20-25 wt. $\%$ and cellulose for 33-40 wt.\% of wheat 
straw [21]. With a yearly production of around 62 million tons [22], lignin can be therefore considered as an interesting feedstock in combustion and gasification processes.

However, due to the high ash content of wheat straw lignin, an investigation of the ash behavior in combustion and gasification reactors is necessary prior to the implementation of this fuel in an industrial plant.

Therefore, the aim of the present paper is to determine the behavior of wheat straw lignin during fluidized bed gasification, performed in a $100 \mathrm{~kW}$ dual fluidized bed (DFB) steam gasification pilot plant, and during fluidized bed combustion, performed in a bench-scale bubbling fluidized bed reactor. The steady-state operation of wheat straw lignin in the $100 \mathrm{~kW}$ DFB steam gasification pilot plant is compared to the operation with a common woody-type biomass. The impact on operation due to formation of coherent ash residues is discussed. Although formation of such coherent ash residues in silica-rich ashes has already been described by several authors, more in-depth characterization as well as the formation mechanism are still missing. This paper therefore provides chemical and morphological characterization using X-ray diffraction (XRD), X-ray fluorescence (XRF) and scanning electron microscopy coupled with energy-dispersive X-ray spectroscopy (SEM-EDS). Furthermore, a formation mechanism including the aspect of fuel treatment for these coherent ash particles is suggested, supported by chemical analysis and thermodynamic equilibrium calculations. Moreover, the influence of fuel pretreatment (pelletizing) on the formation of coherent ash residues is investigated in a bench-scale combustion reactor.

\section{Materials and Methods}

\subsection{Fuel Preparation}

Wheat straw lignin has been supplied in the form of pressed plates and pelletized with the pelletizing machine PP200 from Cissonious to a diameter of $6 \mathrm{~mm}$. The experiment in the $100 \mathrm{~kW}$ DFB pilot plant has been performed with pelletized lignin. For the experiments in the bench-scale reactor, both pelletized and non-pelletized lignin have been used. The composition of wheat straw lignin has been investigated by elemental analysis. The results are presented in Table 1, together with fuel's lower heating value (LHV), water and ash content.

Table 1. Elemental analysis, lower heating value (LHV), water and ash content of wheat straw lignin.

\begin{tabular}{|c|c|c|}
\hline & Unit & Wheat Straw Lignin \\
\hline Water content & wt. $\%{ }^{1}$ & 5.8 \\
\hline Ash content & wt. $\%$ db. ${ }^{2}$ & 9.1 \\
\hline LHV & $\mathrm{MJ} / \mathrm{kg} \% \mathrm{db}$ & 20.15 \\
\hline $\mathrm{C}$ & wt. $\%$ db. & 51.98 \\
\hline $\mathrm{O}$ & wt. $\%$ db. & 31.5 \\
\hline $\mathrm{H}$ & wt. $\%$ db. & 5.57 \\
\hline$n$ & wt. $\% \mathrm{db}$. & 1.69 \\
\hline $\mathrm{S}$ & wt. $\% \mathrm{db}$ & 0.132 \\
\hline $\mathrm{Cl}$ & wt. $\% \mathrm{db}$. & 0.0144 \\
\hline
\end{tabular}

\section{2. $100 \mathrm{~kW}$ DFB Gasification Pilot Plant}

The $100 \mathrm{~kW}$ DFB gasification pilot plant consists of two separate reactors: a gasification reactor (GR) and a combustion reactor (CR). The reactor dimensions are shown in Figure 1. Feedstock is introduced from the hoppers into the lower gasification reactor through a screw conveyor, where it is fluidized with steam in a bubbling fluidized bed regime. The product gas is then transported 
through the upper gasification reactor into the gravity separator, where it is separated from the bed material. The GR is connected with the CR via the upper loop seal and the lower loop seal. The bed material in the $C R$ is fluidized with air (fast fluidization). The heat necessary for the gasification reactions is produced by the combustion of char and heating oil in the CR and transported into the GR via the bed material. The fine ash is removed from both cyclones regularly, whereas the coarse ash from the lower loop seal is only removed at the end of the experiment. The product gas components $\mathrm{CO}, \mathrm{CO}_{2}, \mathrm{CH}_{4}, \mathrm{O}_{2}$ and $\mathrm{H}_{2}$, as well as flue gas components $\mathrm{CO}, \mathrm{CO}_{2}, \mathrm{O}_{2}, \mathrm{SO}_{2}, \mathrm{NO}, \mathrm{NO}_{2}$ and $\mathrm{N}_{2} \mathrm{O}$, are continuously measured by the online gas measurement Rosemount NGA2000. The compounds ethane, ethene and propane are furthermore measured by an online gas chromatograph Perkin Elmer Clarus 500 in 12-15 min intervals. Tars are isokinetically sampled (discontinuously) and consequently measured by gas chromatography mass spectrometry (GCMS) using the Perkin Elmer Autosystem $\mathrm{XL}$ gas chromatograph with the Perkin Elmer Turbomass mass spectrometer. The analysis process, calculation and sampling for tar is more closely described in Reference [23]. Temperature is measured by type $\mathrm{K} \mathrm{Ni} / \mathrm{CrNi}$ thermocouples with a range between -270 and $1270{ }^{\circ} \mathrm{C}$. Pressure measurement is carried out using Endress Hauser (0-1 bar), Kalinski (0-500 mbar) and Rosemount (0-1 mbar) pressure sensors. At the beginning of the experiment, both reactors were preheated with electrical heaters and by combustion of heating oil and softwood pellets. During the heating phase, air was used as the fluidizing medium in both reactors.
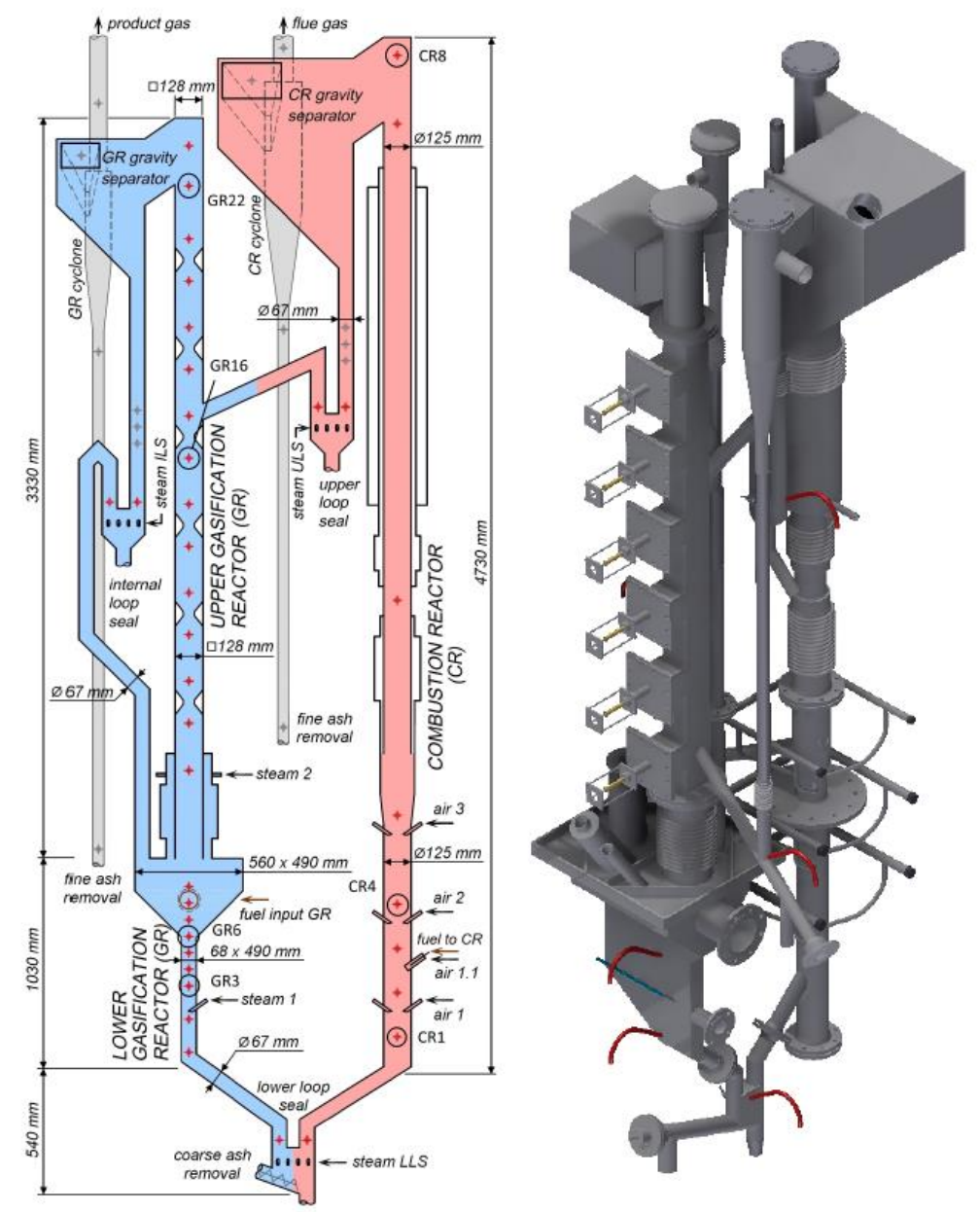

Figure 1. Scheme and 3Ddrawing of the $100 \mathrm{~kW}$ dual fluidized bed (DFB) steam gasification pilot plant [23].

Afterwards, the fluidization medium in the GR was gradually switched from air to steam. In the case of lignin, a gasification steam to fuel ratio of $1.0 \mathrm{~kg}$ steam $/ \mathrm{kg}_{\text {fuel,db. }}$ and a feedstock mass 
flow of $19.7 \mathrm{~kg} / \mathrm{h}$ were used [24]. Prior to wheat straw lignin gasification, softwood has been used as a benchmark feedstock, with a feedstock mass flow of $21.2 \mathrm{~kg} / \mathrm{h}$ and steam to fuel ratio of $0.9 \mathrm{~kg}$ steam $/ \mathrm{kg}_{\text {fuel, } \mathrm{db}}$. The temperature and the pressure were continuously measured at different points of the GR and the CR. At the end of the experiment, the bed material was released and samples of bed material as well as bed ash were collected.

\subsection{Bench-Scale Bubbling Fluidized Bed Combustion Reactor}

The bench-scale bubbling fluidized bed reactor was used to investigate the influence of fuel pelletizing and oxidizing atmosphere on the formation of coherent ash residues. Therefore, both pelletized and non-pelletized fuel were used for the experimental investigations.

The cylindrical fluidized bed reactor is constructed from stainless steel with an inner diameter of the fluidized bed section of $13.6 \mathrm{~cm}$ and the freeboard section with a diameter of $30 \mathrm{~cm}$. The feedstock can be supplied continuously by two separate screw conveyors from 2 individual hoppers, with the volumes of 15 and $100 \mathrm{~L}$. Both hoppers are flushed with $\mathrm{N}_{2}$ in order to secure an inert atmosphere in the hopper and in the screw conveyor. The distribution of the air is realized through the air nozzles at the bottom of the reactor. Constant air flow secures the bubbling bed regime and total combustion of the fuel. Produced gas is led from the reactor to the cyclone, where the fly ash is separated from the gas stream. Part of the gas is also bypassed to a gas analyzer, where the content of $\mathrm{O}_{2}, \mathrm{CO}_{2}, \mathrm{CO}, \mathrm{H}_{2}$ and $\mathrm{CH}_{4}$ is continuously measured. The remaining part of the gas is fed to the torch, where it is burnt with a $\mathrm{CH}_{4}$ flame. A simplified scheme of the bubbling fluidized bed reactor is shown in Figure 2.

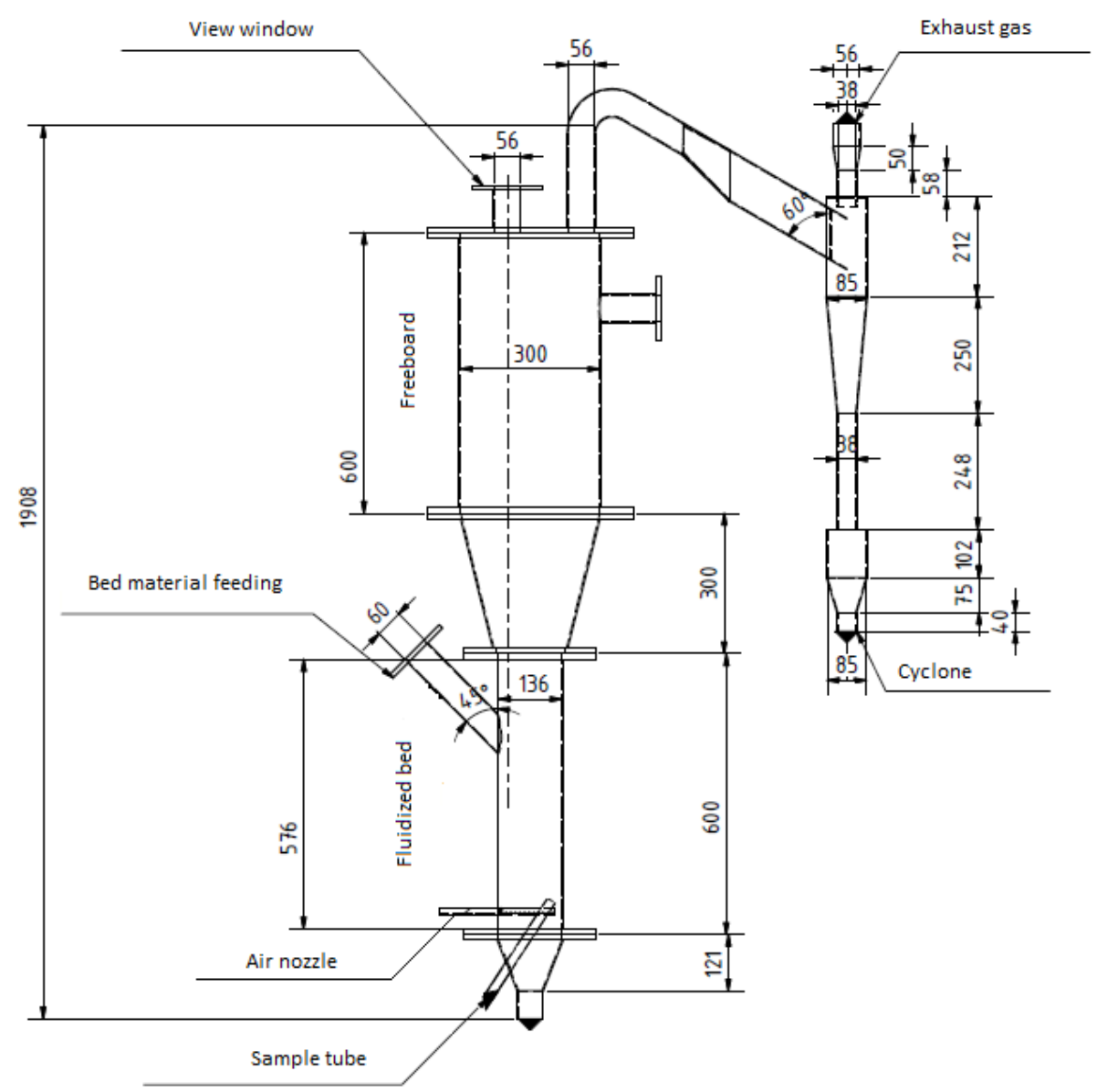

Figure 2. Scheme of the bench-scale bubbling fluidized bed reactor. All dimensions are in mm.

In the case of both feedstocks: pelletized and non-pelletized wheat straw lignin, $5.5 \mathrm{~kg}$ of quartz was used as a bed material. However, part of the bed material (up to $40 \%$ ) was beneath the fluidization 
nozzles and did not actively participate in the bubbling fluidized bed. $200 \mathrm{Nl} / \mathrm{min}$ of air was used as a fluidizing medium, insuring the bubbling bed regime in the reactor. In the case of non-pelletized lignin, fuel was supplied continuously. As for the pelletized lignin, on- and off-operation was necessary, since the heat produced during the combustion rapidly increased the bed temperature. The temperatures and the pressure drop in the fluidized bed were continuously measured.

\subsection{XRF Analysis}

Ash samples of pelletized feedstock as well as samples from the experiments in the $100 \mathrm{~kW}$ DFB steam gasification pilot plant were subjected to $\mathrm{X}$-ray fluorescence (XRF) analysis. $1 \mathrm{~g}$ of the ash sample was mixed together with $9 \mathrm{~g}$ of $\mathrm{Li}_{2} \mathrm{~B}_{4} \mathrm{O}_{7}$, melted on a platinum crucible at $1050{ }^{\circ} \mathrm{C}$ and cast into a mold with a flat bottom. The XRF analysis was then carried out by a PANalytical Axios Advanced analyzer, which works in a vacuum with a Rh anode. An excitation voltage of $50 \mathrm{kV}$ and a tube current of $50 \mathrm{~mA}$ have been used.

\subsection{SEM Analysis}

The examined material was mounted in epoxy and polished to obtain cross-sections of the particle. Analysis was performed with a combined scanning electron microscope (SEM) and energy-dispersive X-ray spectroscopy (EDS). EDS area mappings and line scans were obtained. The sample's layer morphology was determined with a Zeiss Evo LS-15 at a voltage of $20 \mathrm{kV}$ and a current of $400 \mathrm{pA}$ in backscattered mode. Furthermore, an elemental composition was determined using an Oxford X-MaxN 80 EDS detector.

\subsection{XRD Analysis}

XRD data collection was performed with a PANalytical MPD Pro Instrument with an optical configuration consisting of $\mathrm{Cu} \mathrm{K} \alpha$ radiation, and a X-Celerator detector. As a result, qualitative information on the present crystalline phases was gained.

\subsection{Thermodynamic Equilibrium Calculation}

Thermodynamic equilibrium calculations were performed using the software FactSage 7.3-a fully integrated thermochemical software and database package [25]. Calculations were carried out in the Equilib module, which employs the Gibbs energy minimization algorithm and thermochemical functions. FactPS, FToxid and FTsalt were chosen as databases. The ash composition was used as a reactant stream. Calculations were performed solely in oxidizing atmosphere, since according to Boström et al. [15], most ash-forming elements will stay as oxides under all conversion conditions. This is caused by the fact that oxygen from fuel will bond with the ash-forming elements prior to carbon. Consequently, the difference between calculations in both oxidizing and reducing atmosphere should be negligible.

\section{Results and Discussion}

\subsection{Operation Performance in the $100 \mathrm{~kW}$ DFB Gasification Pilot Plant}

Gasification of wheat straw lignin resulted in an overall promising performance regarding the conversion into product gas of similar quality as when softwood is used as fuel. The results will be presented and discussed in more detail in the following subsections.

Figure 3 shows the temperature (T GR1, T GR6 and T GR15) and pressure (P GR1, P GR6 and P GR15) profile of the operation of wheat straw in the gasification reactor of the DFB system. It can be seen that the fluctuation of both the bed temperature and pressure increases with progressing operating time. Locations of the temperature and pressure measurement points (GR1, GR6 and GR15) in the gasification reactor are shown in the schematic display of the gasification reactor next to the diagram. 


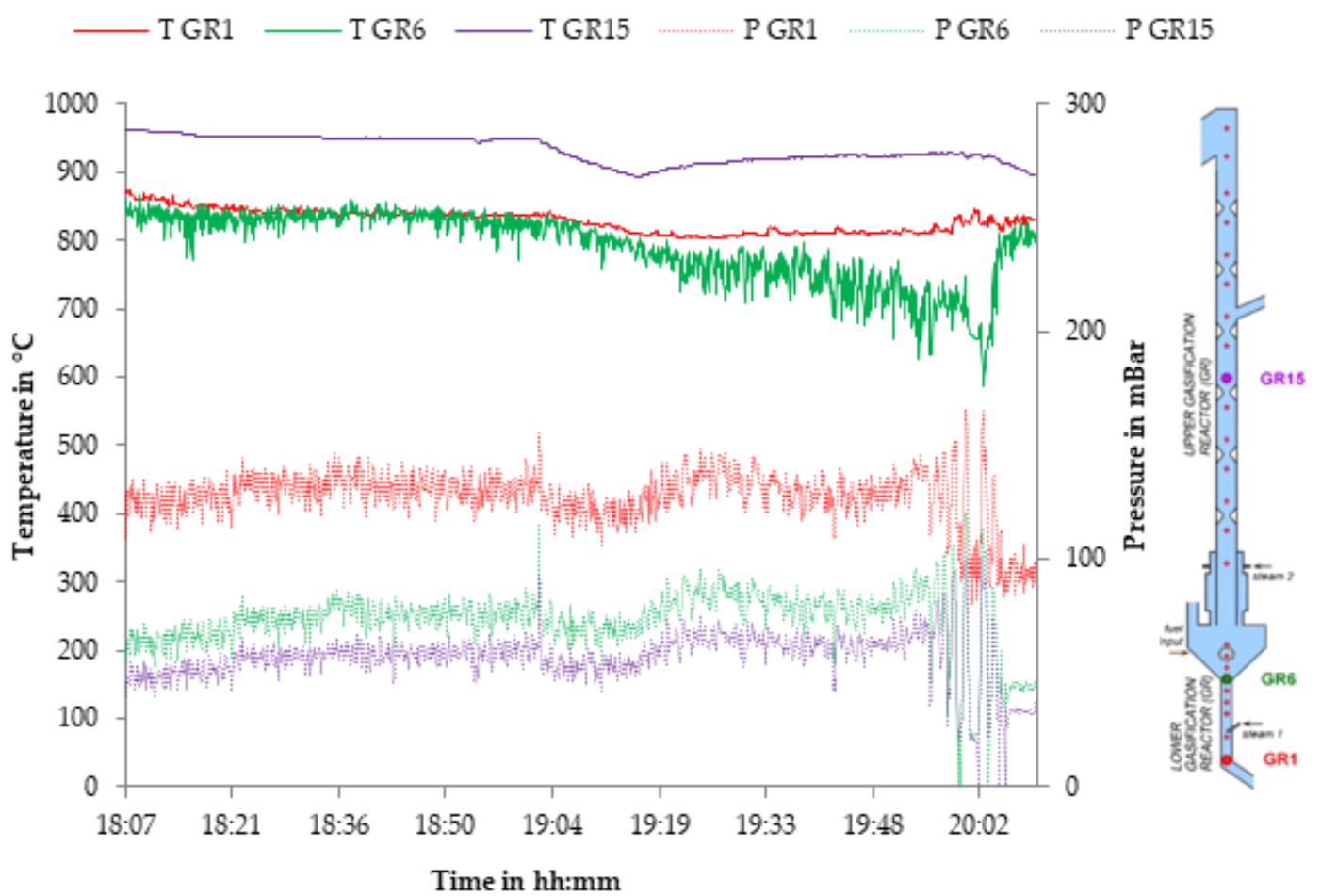

Figure 3. Left: Temperature and pressure measurement of gasification reactor at measurement points GR1, GR6 and GR15. Right: scheme of gasification reactor with the measurement points [23].

During sampling of ash (during and after the experiment), an accumulation of coherent ash residues in the bed could be observed. The accumulation of those coherent ash residues led to an overload of floating particles on the bed surface, which negatively influences the operation of the reactor. A stable fluidization could not be ensured in the gasification reactor.

Table 2 shows the product gas composition given in volume percentage $\left(v_{\mathrm{pol}} \%_{\mathrm{db}}\right.$.) from the experiment with softwood and wheat straw lignin in the $100 \mathrm{~kW}$ DFB gasification pilot plant. $\mathrm{Th}^{\mathrm{H}} \mathrm{H}_{2}$ content was slightly above $40 \%, \mathrm{CO}$ and $\mathrm{CO}_{2}$ contents were around $20-22 \%$ and methane content was slightly above $10 \%$. The main product gas composition of wheat straw lignin gasification is therefore comparable to the quality of product gas gained from gasification of softwood and other lignocellulosic and residual biogenic fuels, such as rice husk, hazelnut shells, bark, sugar cane bagasse, etc., in the 100 kW DFB gasification pilot plant [23]. In Güssing, Austria, where the combined heat and power (CHP) plant with a fuel capacity of $8 \mathrm{MW}$ has been in operation for more than $2500 \mathrm{~h}$, similar gas composition has been reached by gasifying wood chips [26].

Table 2. Composition of product gas in volume percentage (vol. $\% \mathrm{db}$.) from the experiments with softwood and wheat straw lignin in the $100 \mathrm{~kW}$ DFB gasification pilot plant [23].

\begin{tabular}{cccc}
\hline & Unit & Softwood & Wheat Straw Lignin \\
\hline $\mathrm{H}_{2}$ & vol. $\% \mathrm{db}$. & 47.4 & 40.6 \\
\hline $\mathrm{CO}$ & vol. $\% \mathrm{db}$. & 21.3 & 20.2 \\
\hline $\mathrm{CO}_{2}$ & vol. $\% \mathrm{db}$. & 21.2 & 20.8 \\
\hline $\mathrm{CH}_{4}$ & vol. $\% \mathrm{db}$. & 8.9 & 11.4 \\
\hline $\mathrm{C}_{2} \mathrm{H}_{4}$ & vol. $\% \mathrm{db}$. & 0.5 & 2.3 \\
\hline
\end{tabular}

Based on power input heat losses and composition of product gas, overall cold gas efficiency as well as product gas output power was calculated. The values are shown in Table 3 together with the mean temperatures of the gasification and combustion reactors. The overall cold gas efficiency 
$(\sim 72 \%)$ could be further increased by reducing radiative heat loss of the $100 \mathrm{~kW}$ DFB gasification pilot plant, which accounts for almost $15 \%$ of GR fuel input power. However, the calculated overall cold gas efficiency of wheat straw lignin is in a similar range with the other lignocellulosic fuels [23].

Table 3. Mean temperature in the gasification and combustion reactors (GR and CR), fuel and heating power input, product gas (PG) power output, heat losses of GR and CR and calculated overall cold gas efficiency of the $100 \mathrm{~kW}$ DFB gasification pilot plant.

\begin{tabular}{cccc}
\hline & Unit & Softwood & Wheat Straw Lignin \\
\hline Temperature in GR ${ }^{1}$ & ${ }^{\circ} \mathrm{C}$ & 827 & 789 \\
\hline Temperature in CR & ${ }^{\circ} \mathrm{C}$ & 985 & 966 \\
\hline Fuel power input & $\mathrm{kW}$ & 99.7 & 101.8 \\
\hline Heating oil input & $\mathrm{kW}$ & 45.3 & 44.4 \\
\hline PG output power & $\mathrm{kW}$ & 96.1 & 95.7 \\
\hline Heat losses (GR and CR) & $\mathrm{kW}$ & 14.9 & 10.7 \\
\hline Overall cold gas efficiency & $\%$ & 71.6 & 72.8 \\
\hline${ }^{1}$ Mean temperature in bubbling bed of lower gasification reactor.
\end{tabular}

The tar content of the product gas from wheat straw lignin gasification shown in Figure 4 is almost twice as high as in the case of softwood gasification. This originates from the lignin molecular structure, which is composed mostly of aromatic units such as hydroxyphenyl, guaiacyl and syringil [27], and therefore, the tar yield of lignin is considerably higher in comparison to a cellulose- and hemicellulose-based feedstock such as softwood [28]. BTEX (a mixture of benzene, toluene, ethylbenzene and xylene) tars are shown in Figure 4 separately. Both dust and flue coke were measured in the course of the tar measurement protocol described in References [29,30]. In the case of flue coke and dust, the measurement results were within the same range for both cases. These results also correspond well with the experiment with other lignocellulosic fuels performed in the $100 \mathrm{~kW}$ DFB gasification pilot [23].

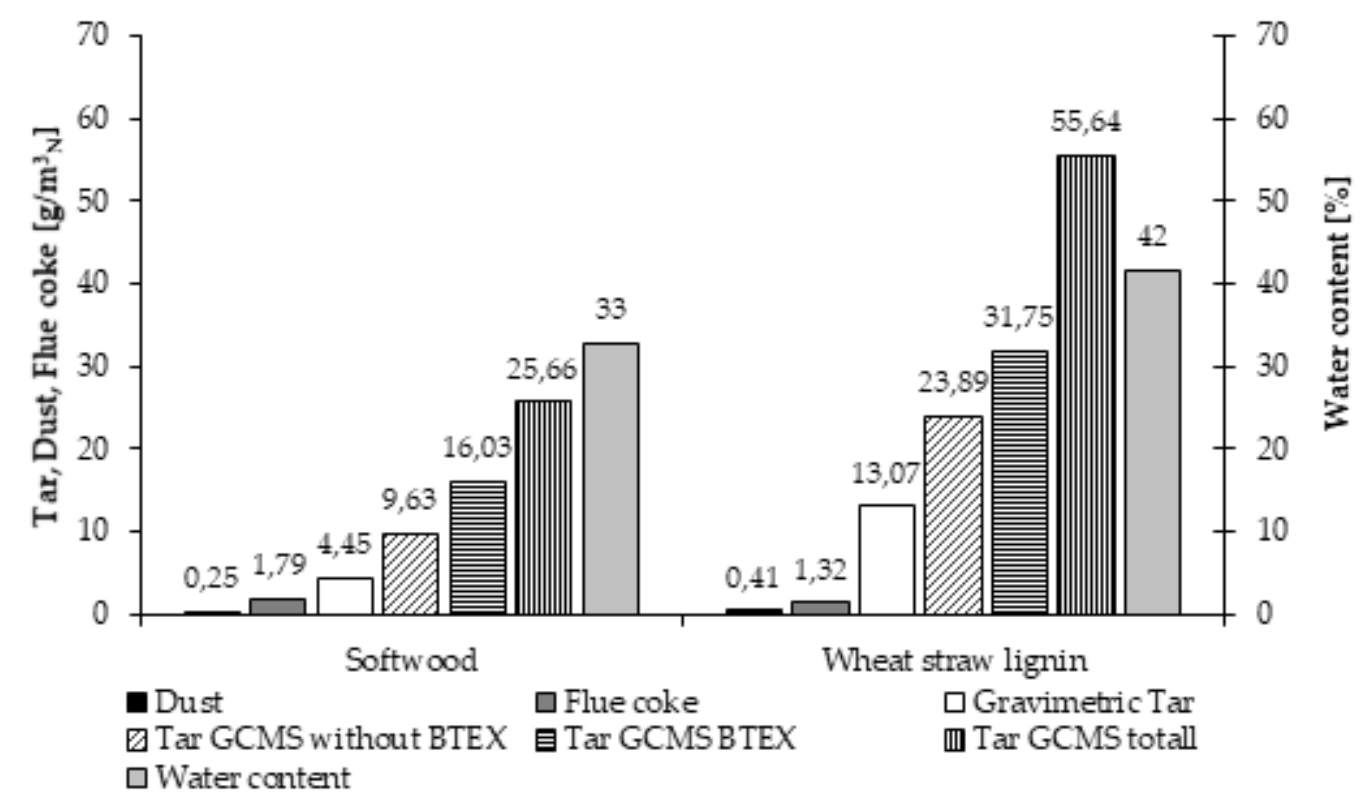

Figure 4. Left: Amount of tar, dust, flue coke and water in product gas from gasification of softwood. Right: Amount of tar, dust, flue gas and water in product gas from gasification of wheat straw lignin. 
Since only a single experiment with wheat straw lignin has been performed in the $100 \mathrm{~kW}$ DFB gasification pilot plant so far, the reproducibility as well as the standard deviation of the experiment cannot be stated. More experiments are therefore necessary in order to provide a sufficient amount of data for the data analysis.

In conclusion, the experimental test run in the $100 \mathrm{~kW}$ DFB gasification pilot plant showed that wheat straw lignin is a generally suitable feedstock for fluidized bed gasification. However, some specific measures need to be taken to encounter the accumulation of coherent ash residues on the surface of the bed, e.g., their continuous discharge from the reactor. Furthermore, higher amounts of produced tar and dust (in comparison to a woody biomass) need to be accounted for by designing the product gas cleaning process accordingly. Especially, higher amounts of tars can cause operational problems, since heavy tars may condense afterwards on cooled surfaces in downstream cleaning processes and create blockages in particle filters and pipelines. Moreover, formation of aerosols and soot due to repolymerization of tar compounds is also possible and negatively influences the plant operation [27].

\subsection{Formation of Coherent Ash Residues}

Influence of coherent ash residues on the process performance of the $100 \mathrm{~kW}$ DFB pilot plant has already been described in the previous section. Formation of ash residues as well as its dependency on the fuel pretreatment will be discussed in more detail in the following.

Typically, fuel particles can burn in a fluidized bed either according to the shrinking core or the shrinking particle model [31]. According to the shrinking particle model, which is typical for low-ash fuel such as softwood, combustion of the fuel particle takes place at constant particle density. The reaction with oxygen takes place at the surface of the particle and the produced ash is due to abrasive forces separated from the particle. In the case of the shrinking core model, the unreacted core is surrounded by an expanding layer of coherent ash that withstands abrasive forces of bed material. As a result, coherent ash residues may be formed, such as those found in the experiment with wheat straw lignin in the $100 \mathrm{~kW}$ DFB pilot plant.

Formation of coherent ash residues is not only limited to wheat straw lignin-a similar phenomenon was already observed by combustion of, for example, rice hulls and sewage sludge [32-35]. Canò et al. [36] studied the ash behavior of sewage sludge in more detail and presented a single particle model of a char particle for the fluidized bed combustion. The model combines both the shrinking particle and shrinking core conversion pattern. Carbon combustion is represented with the shrinking core feature, in which the unburned carbon core is surrounded by an expanding coherent ash layer. The coherent ash layer is resistant to mechanical attrition and provides an additional resistance for mass and heat transfer (due to a decrease of the ash thermal conductivity) towards the carbon core. A decrease in the ash thermal conductivity results in the overheating of the particle core, which may approach $1015^{\circ} \mathrm{C}$. The second feature of the model, a shrinking particle conversion pattern, represents the attrition of the ash layer due to particle collisions.

Similar observations have been made by Troiano et al. [37], who studied combustion of lignin-rich residues from bioethanol production in a fluidized bed. According to the authors, the fuel particles did not undergo primary fragmentation during devolatilization. Moreover, secondary fragmentation that occurred during char burn-out was not linked to the loss of connectivity in the char structure (as it is in the case of softwood), but was caused by mechanical attrition due to collisions with other fluidized particles. They concluded that char combustion of lignin-rich residues takes place according to the shrinking core model rather than according to the shrinking particle model.

This conclusion corresponds well with the results of the experiments presented in this paper. Most coherent ash residues maintain the shape of the original pellets throughout the experiment in both reactors. Although they were reduced in size (in comparison to original pellets), no, or only very limited primary fragmentation occurred. 
In order to investigate the influence of the combustion atmosphere and the fuel pretreatment on the formation of coherent ash residues, two additional experiments have been performed in a bench-scale fluidized bed reactor. The bed temperature was manually kept below $720^{\circ} \mathrm{C}$ to produce a certain amount of ash in the system. The steady-state operation at constant temperatures was kept for approximately $3 \mathrm{~h}$ and ash samples were collected afterwards.

Visual examination of the ash residues, sampled from the bench-scale experiments, showed significant differences between pelletized and non-pelletized wheat straw lignin ash residues. Thermo-chemical conversion of the non-pelletized feedstock resulted in formation of less stable ash residues with cracks along the layers of the lignin plates. These cracks are the most likely reason for the lower mechanical stability of the ash particles, resulting in higher attrition and subsequently, smaller ash particles. Thermo-chemical conversion of pelletized feedstock leads to the formation of more stable coherent ash particles. The surface of these particles is smooth, and in contrast to non-pelletized feedstock, no visible cracks occur. The smoother surface can be associated with a molten surface of the pelletized particles, which increases the stability.

Figure 5 shows a simplified scheme explaining the conversion of pelletized and non-pelletized wheat straw lignin. The simplified scheme describes the dominance of the fuel treatment process of pelletizing regarding the formation of coherent ash residues. Through pelletizing, the particle's hardness and density is being enhanced under mechanical pressure and elevated temperatures. The pelletizing process also improves solid-solid contacts inside the particle, increasing its thermal conductivity [38], which can lead to more extensive local overheating. Moreover, the increase in solid-solid contacts considerably improves the probability of reactions among the ash-forming elements, leading to more extensive slag formation. Consequently, combustion of non-pelletized feedstock leads to the formation of less stable ash residues and therefore to higher attrition of particles and their elutriation from the bubbling bed. Moreover, severe cracks are formed along the layers of the lignin plates. As a consequence of this cracking, the lignin layers split open and the fuel particle size is significantly decreased.

Wheat straw lignin pellets:

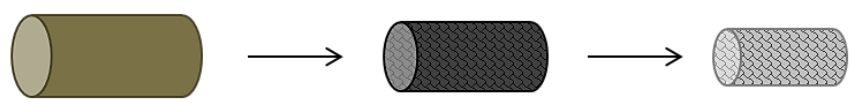

Non-pelletized wheat straw lignin:

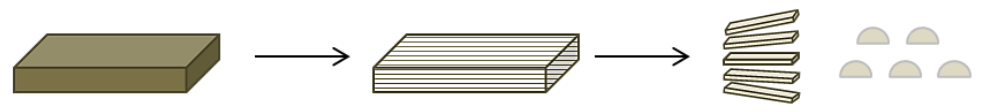

Figure 5. Simplified scheme of the conversion of pelletized and non-pelletized wheat straw lignin.

To conclude, even though the formation of coherent ash residues could be observed in combustion of both pelletized and non-pelletized wheat straw lignin, the phenomenon is significantly more pronounced for pelletized wheat straw lignin. Combustion of non-pelletized lignin therefore leads to less stable ash residues with severe cracks, which prohibits their attrition and subsequent elutriation from the bed.

In their work [39], Liakakou et al. also emphasize the importance of fuel pretreatment in the gasification process. Smaller fuel particles have larger surface areas, which allows better mass and heat transfer and increases reaction rates. On the other hand, fine particles may cause difficulties in fuel feeding, and at higher gas velocities, may be entrainment from the fluidized bed reactor. Consequently, they used milled wheat straw lignin (with particle size between 2 and $10 \mathrm{~mm}$ ) in their experiments in a bubbling fluidized bed gasification reactor. Although the ash composition of the wheat straw lignin 
used in their experiments is very similar to the one used in this paper, Liakakou et al. did not observe formation of coherent ash residues. This underlines the effect of pelletizing and of fuel size on the formation of coherent ash residues.

\subsection{Characterization of Coherent Ash Residues}

Samples of the ash residues from the $100 \mathrm{~kW}$ DFB gasification pilot plant were collected after the experiment and further investigated by XRF, SEM, XRD and elemental analysis through EDS measurements.

Results of the XRF analysis, displayed in Table 4, show that the composition of the feedstock ash produced according to EN ISO 18122 norm (referred to as wheat straw lignin ash) is similar to the composition of coherent ash residues after gasification in the $100 \mathrm{~kW}$ DFB gasification pilot plant (referred to as wheat straw lignin ash residues). The composition of the ash residues from gasification of rice husks, which show similar melting behavior as wheat straw lignin [32,33] and softwood in the $100 \mathrm{~kW}$ DFB steam gasification pilot plant, is included inTable 4. Compared to softwood, both wheat straw lignin and rice husks have significantly higher shares of $\mathrm{Si}$ in the ash composition and hence it can be presumed that high amounts of silica play an important role in the formation of coherent ash residues.

Table 4. X-ray fluorescence (XRF) analysis of wheat straw lignin ash residues, wheat straw lignin ash, softwood ash and rice husk ash [33].

\begin{tabular}{cccccc}
\hline Oxide & Unit & Lignin Ash Residues & Lignin Ash & Softwood Ash & Rice Husk Ash \\
\hline $\mathrm{Fe}$ & wt. $\%$ & 0.56 & 0.50 & 0.70 & 0.35 \\
$\mathrm{Ca}$ & wt. $\%$ & 2.46 & 2.69 & 43.74 & 0.58 \\
$\mathrm{~K}$ & wt. $\%$ & 2.25 & 2.56 & 12.33 & 1.34 \\
$\mathrm{P}$ & wt. $\%$ & 0.54 & 0.54 & 1.50 & 0.35 \\
$\mathrm{Si}$ & wt. $\%$ & 40.45 & 39.48 & 3.42 & 43.21 \\
$\mathrm{Al}$ & wt. $\%$ & 0.73 & 1.39 & 0.94 & 1.12 \\
$\mathrm{Mg}$ & wt. $\%$ & 0.60 & 0.21 & 5.55 & 0.30 \\
$\mathrm{Na}$ & wt. $\%$ & 1.42 & 1.10 & 0.90 & 0.90 \\
$\mathrm{~S}$ & wt. $\%$ & 0.10 & 0.51 & - & - \\
$\mathrm{O}$ & wt. $\%$ & 50.28 & 50.13 & 30.92 & 51.84 \\
\hline
\end{tabular}

SEM analysis of the ash residues from gasification provides more information about the distribution of individual elements in the particle. As it can be seen in Figure 6, Si and K are uniformly distributed among the ash particles, which could support the reactions between $\mathrm{Si}$ and $\mathrm{K}$. As already mentioned in the introduction, these reactions may lead to the formation of low-melting potassium silicates and hence to the melting of ash. Ca is also found throughout the particle, however some areas have higher $\mathrm{Ca}$ - concentrations are distinguishable. Even though XRF analysis shows a relatively high Na content (1:1 relation between $\mathrm{K}$ and $\mathrm{Na}$ ), $\mathrm{Na}$ could not be detected by EDS analysis. This could be reasoned by an uneven distribution of the element in the samples. Traces of other elements such as $\mathrm{P}, \mathrm{S}, \mathrm{Fe}$ and $\mathrm{Cl}$ were not visible in any of the EDS images either.

XRD analysis of the coherent ash residues from the experiment in the $100 \mathrm{~kW}$ DFB steam gasification pilot plant, displayed in Figure 7, shows that a significant part of the particle content is present in amorphous form, which can be observed as an enhanced background in XRD pattern. This originates from amorphous silica as well as from melted alkali silicates, in which other components such as earth alkali oxides are subsequently dissolved [15]. The crystalline phase is represented by cristobalite (with a distinguished peak between 21 and $22^{\circ} 2$ Theta), quartz (peaks at 20, 27 and $50^{\circ} 2$ Theta) and arcanite $\mathrm{K}_{2} \mathrm{SO}_{4}(\mathrm{~s})$ (with peaks between 29 and 31,40 and 41 and $43^{\circ} 2$ Theta). However, due to ash compositions' complexity, the exact calculation of amorphous and crystalline phase amounts was not possible. 

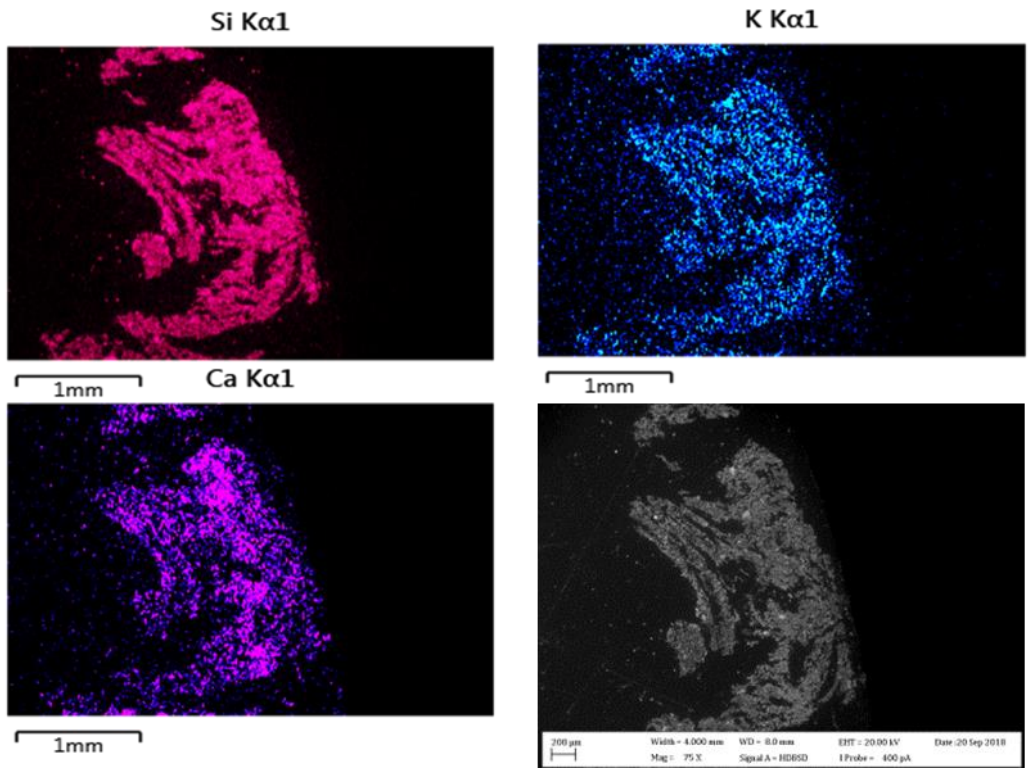

Figure 6. Energy-dispersive X-ray spectroscopy (EDS) elemental mappings ( $\mathrm{Si}, \mathrm{K}, \mathrm{Ca}$ ) as well as a scanning electron microscopy (SEM) image (bottom, right) of an ash residue particle sampled from the $100 \mathrm{~kW}$ DFB gasification pilot plant.

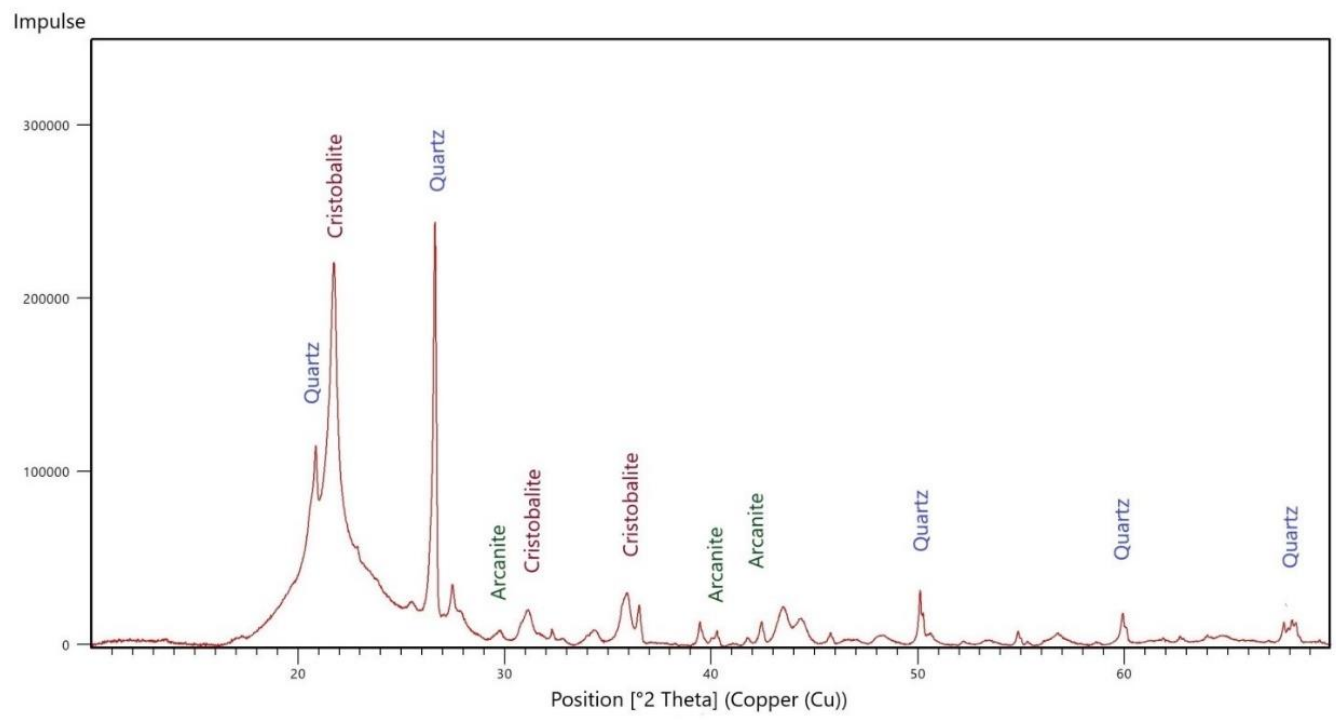

Figure 7. X-ray diffraction (XRD) analysis of the coherent ash particle from the experiment in the $100 \mathrm{~kW}$ DFB gasification pilot plant.

Formation of cristobalite in the DFB reactor is particularly interesting. Following the theoretical sequence of the silica transformations upon heating, the most stable polymorph at atmospheric pressure and combustion temperatures would be quartz (up to $573{ }^{\circ} \mathrm{C}$ ) and tridymite (between 573 and $1470^{\circ} \mathrm{C}$ ) [40-42]. However, in some cases (depending on temperature and impurities), cristobalite may be the first phase to form, although it is out of its thermodynamic stability range. This is an example of Ostwald's rule, which states that the solid first formed on crystallization of a melt or a solution would be the least stable polymorph [43].

\subsection{Thermodynamic Equilibrium Modelling}

The formation of a melting phase has been predicted by equilibrium calculation performed in Factsage 7.3. Below $660^{\circ} \mathrm{C}$, most of $\mathrm{K}$ and $\mathrm{Na}$ is present in the form of $\mathrm{Na}_{2} \mathrm{Ca}_{3} \mathrm{Si}_{6} \mathrm{O}_{16}, \mathrm{Na}_{2} \mathrm{CaP}_{2} \mathrm{O}_{7}$, 
feldspar $\left(\mathrm{KAlSi}_{3} \mathrm{O}_{8}-\mathrm{NaAlSi}_{3} \mathrm{O}_{8}-\mathrm{CaAl}_{2} \mathrm{Si}_{2} \mathrm{O}_{8}\right)$ and halite $(\mathrm{NaCl})$. The first molten phase is formed above $660{ }^{\circ} \mathrm{C}$, composed mainly of alkali silicates. Molten phase, as well as quartz, is displayed in Figure 8 on the secondary axe (right side), since its amount is considerably higher in comparison to other present phases, which are displayed on the primary axe (Figure 8, left side). Alongside the molten phase, wollastonite and arcanite are formed as well, since $\mathrm{Ca}$ and $\mathrm{S}$ are due to the decay of the above-mentioned phases available for further reaction. The amount of molten phase increases continuously up to $920^{\circ} \mathrm{C}$. Afterwards, the amount of molten phase is steeply increased from $8 \mathrm{wt} . \%$ up to $30 \mathrm{wt}$. \% between 920 and $940^{\circ} \mathrm{C}$, accompanied by the decay of feldspar.

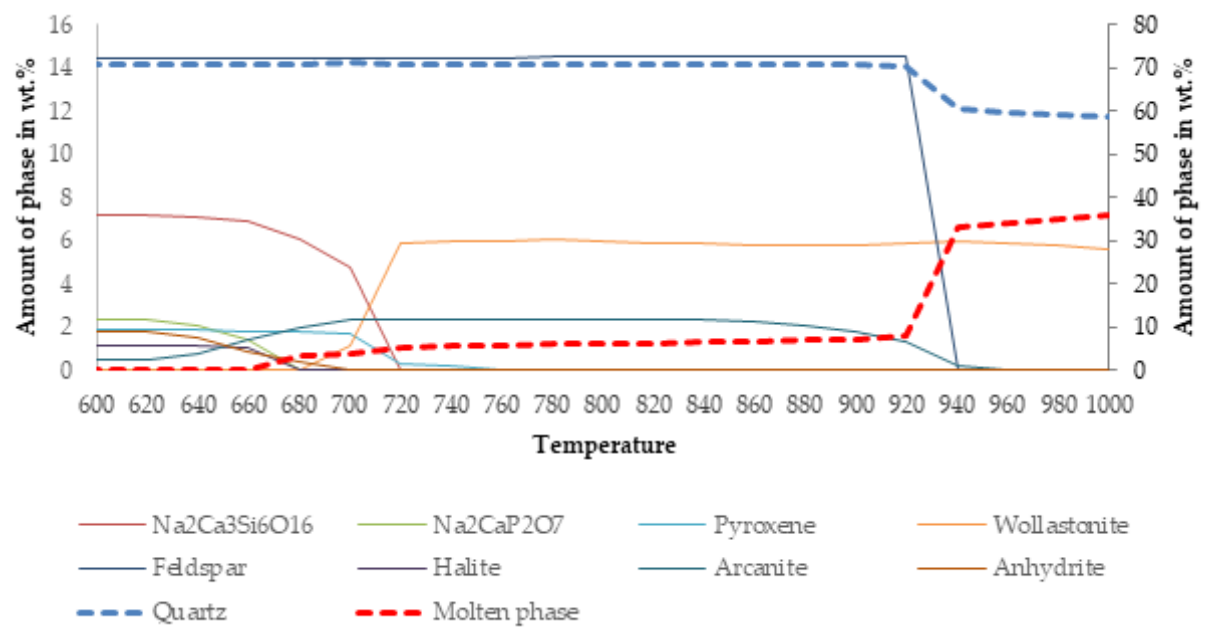

Figure 8. Equilibrium calculation based on composition of coherent ash residues from the gasification experiment in the $100 \mathrm{~kW}$ DFB pilot plant.

Although equilibrium calculations predict melting of the ash, bed agglomeration did not occur during the experiments in the fluidized bed reactors. A possible reason could be a low fraction of the molten phase, which represents only $5-10 \%$ of the total ash amount at the operation temperatures.

It has been observed that the amount of molten phase in the particle is an important factor in this context, since it is directly linked to the stickiness of the particle [44]. Backman et al. have therefore initiated the concept of using $T_{0}, T_{15}, T_{30}, T_{70}$ and $T_{100}$ to indicate the temperatures at which the liquid content is 0, 15, 30, 70 and $100 \mathrm{wt} . \%$, respectively [45]. Evic et al. [46] studied correlation between the results from thermodynamic equilibrium calculations and the experimental data (using thermogravimetric analysis and differential scanning calorimetry) of biomass ashes in more detail. Based on their experiences, temperature range between $\mathrm{T}_{15}$ and $\mathrm{T}_{30}$ (corresponding to a temperature with $15 \mathrm{wt} . \%$ and $30 \mathrm{wt} . \%$ molten phase, respectively) is recommended for comparison between the experimental results and the results from thermodynamic equilibrium calculations for biomass ashes.

Consequently, due to the low amount of molten phase in the ash residues, bed agglomeration will not occur during lignin combustion and gasification. Nevertheless, partial melting of the ash is probably the reason for formation of coherent ash residues, which are due to their mechanical strength resistant to abrasive forces and hence will not be fragmented and entrained with a fluidization agent from the reactor.

Thermodynamic equilibrium calculations correspond well with the results of XRD analysis. Molten phase, which has been predicted by equilibrium calculations already at $660^{\circ} \mathrm{C}$, is also recognizable in the XRD pattern (Figure 7) as an enhanced background. Major XRD peaks belong to $\mathrm{SiO}_{2}$, which is present either in the form of quartz or cristobalite. However, as mentioned before, cristobalite is thermodynamically not stable below $1470{ }^{\circ} \mathrm{C}$ and therefore is not predicted by thermodynamic equilibrium calculations. The presence of other crystal phases, except for arcanite, have been not confirmed in the coherent ash residues, probably due to the complexity of the ash composition. 


\section{Conclusions}

The results of the experiments show that leached lignin derived from wheat straw could be a suitable feedstock for DFB steam gasification. A product gas with quality comparable to the one obtained with softwood could be produced. However, slightly higher amounts of produced tars need to be taken into account. The formation of coherent ash particles was observed during thermo-chemical conversion leading to fluidization issues and thus, negatively impacting the process. Progressive accumulation of these ash residues at the bed surface have led to bed temperature fluctuations and changes in fluidization dynamics.

The coherency of the ash residues is most likely caused by an evenly distributed silica-rich molten phase, consisting mostly of K- and Na-Silicates. This statement is supported by the results of EDS and XRD analysis, as well as by thermodynamic equilibrium calculations performed in FactSage 7.3. Furthermore, the thermodynamic equilibrium calculations predict only partial melting (5-10 wt.\%) of the ash residues, which eventuates in their low stickiness. Consequently, no agglomeration occurs during gasification and combustion of wheat straw lignin in the fluidized bed reactor.

Further experiments focused on the influence of fuel pelletizing have led to the conclusion that ash particles from thermo-chemical conversion of pelletized lignin are characterized by a sintered surface, which increases mechanical stability of the particles. Conversion of non-pelletized lignin leads to a formation of cracks along the lignin layers, which increases attrition of the ash particles in the fluidized bed reactor. However, the mechanical characteristic of the ash residues is not part of this paper and further investigations would be necessary in order to fully understand the influence of feedstock form on the strength of the ash particles.

Furthermore, additional investigations into the detailed reaction mechanism underlying the formation of coherent ash residues would be necessary to generalize the results gained in this study as a way to predict such a formation of coherent ash residues to other fuels.

Author Contributions: Conceptualization, J.P. and M.K.; methodology, J.P. and M.K.; software, J.P.; validation, N.S.; formal analysis, J.P.; investigation, J.P., K.F. and F.B.; resources, J.P.; data curation, J.P., K.F. and F.B.; writing —original draft preparation, J.P.; writing—review and editing, K.F., M.K., N.S. and F.B.; visualization, J.P.; supervision, M.K. and H.H.; project administration, M.K.; funding acquisition, M.K. All authors have read and agreed to the published version of the manuscript.

Funding: This research received no external funding.

Acknowledgments: This study was carried out within the BEST-Bioenergy and Sustainable Technologies GmbH project C200410. BEST-Bioenergy and Sustainable Technologies GmbH is funded within the Austrian COMET program, which is managed by the Austrian Research Promotion Agency (FFG) and promoted by the federal government of Austria as well as the federal states of Burgenland, Vienna and Steiermark. We are grateful for the support of our scientific partner, the Institute of Chemical, Environmental and Bioscience Engineering at the TU Wien. Nils Skoglund gratefully acknowledges the financial support from FORMAS Mobility Grant No. 2017-01613. We are grateful for the facilities and technical support (Cheng Choo Lee) of the Umeå Core Facility for Electron Microscopy (UCEM) at the Chemical Biological Centre (KBC), Umeå University.

Conflicts of Interest: The authors declare no conflict of interest.

\section{References}

1. Rogelj, J.; Meinshausen, M.; Knutti, R. Global warming under old and new scenarios using IPCC climate sensitivity range estimates. Nat. Clim. Chang. 2012, 2, 248-253. [CrossRef]

2. Fouilland, T.; Grace, J.R.; Ellis, N. Recent advances in fluidized bed technology in biomass processes. Biofuels 2010, 1, 409-433. [CrossRef]

3. Demirbaş, A. Biomass resource facilities and biomass conversion processing for fuels and chemicals. Energy Convers. Manag. 2001, 42, 1357-1378. [CrossRef]

4. Kraft, S.; Kuba, M.; Kirnbauer, F.; Bosch, K.; Hofbauer, H. Optimization of a 50 MW bubbling fluidized bed biomass combustion chamber by means of computational particle fluid dynamics. Biomass Bioenergy 2016, 89, 31-39. [CrossRef] 
5. Kuba, M.; He, H.; Kirnbauer, F.; Boström, D.; Öhman, M.; Hofbauer, H. Deposit build-up and ash behavior in dual fluid bed steam gasification of logging residues in an industrial power plant. Fuel Process. Technol. 2015, 139, 33-41. [CrossRef]

6. Niu, Y.; Tan, H.; Hui, S. Ash-related issues during biomass combustion: Alkali-induced slagging, silicate melt-induced slagging (ash fusion), agglomeration, corrosion, ash utilization, and related countermeasures. Prog. Energy Combust. Sci. 2016, 52, 1-61. [CrossRef]

7. Skrifvars, B.-J.; Backman, R.; Hupa, M. Characterization of the sintering tendency of ten biomass ashes in FBC conditions by a laboratory test and by phase equilibrium calculations. Fuel Process. Technol. 1998, 56, 55-67. [CrossRef]

8. Öhman, M.; Nordin, A.; Skrifvars, B.-J.; Backman, R.; Hupa, M. Bed Agglomeration Characteristics during Fluidized Bed Combustion of Biomass Fuels. Energy Fuels 2000, 14, 169-178. [CrossRef]

9. Thy, P.; Jenkins, B.M.; Grundvig, S.; Shiraki, R.; Lesher, C.E. High temperature elemental losses and mineralogical changes in common biomass ashes. Fuel 2006, 85, 783-795. [CrossRef]

10. Brus, E.; Öhman, M.; Nordin, A. Mechanisms of Bed Agglomeration during Fluidized-Bed Combustion of Biomass Fuels. Energy Fuels 2005, 19, 825-832. [CrossRef]

11. Kuba, M.; He, H.; Kirnbauer, F.; Skoglund, N.; Boström, D.; Öhman, M.; Hofbauer, H. Mechanism of Layer Formation on Olivine Bed Particles in Industrial-Scale Dual Fluid Bed Gasification of Wood. Energy Fuels 2016, 30, 7410-7418. [CrossRef]

12. He, H.; Ji, X.; Boström, D.; Backman, R.; Öhman, M. Mechanism of Quartz Bed Particle Layer Formation in Fluidized Bed Combustion of Wood-Derived Fuels. Available online: http://pubs.acs.org/doi/full/10.1021/acs. energyfuels.5b02891 (accessed on 9 January 2018).

13. He, H.; Skoglund, N.; Öhman, M. Time-Dependent Crack Layer Formation in Quartz Bed Particles during Fluidized Bed Combustion of Woody Biomass. Energy Fuels 2017, 31, 1672-1677. [CrossRef]

14. Kuba, M.; He, H.; Kirnbauer, F.; Skoglund, N.; Boström, D.; Öhman, M.; Hofbauer, H. Thermal Stability of Bed Particle Layers on Naturally Occurring Minerals from Dual Fluid Bed Gasification of Woody Biomass. Energy Fuels 2016, 30, 8277-8285. [CrossRef]

15. Boström, D.; Skoglund, N.; Grimm, A.; Boman, C.; Öhman, M.; Broström, M.; Backman, R. Ash Transformation Chemistry during Combustion of Biomass. Energy Fuels 2012, 26, 85-93. [CrossRef]

16. Mason, P.E.; Darvell, L.I.; Jones, J.M.; Williams, A. Observations on the release of gas-phase potassium during the combustion of single particles of biomass. Fuel 2016, 182, 110-117. [CrossRef]

17. Knudsen, J.N.; Jensen, P.A.; Dam-Johansen, K. Transformation and Release to the Gas Phase of Cl, K, and S during Combustion of Annual Biomass. Energy Fuels 2004, 18, 1385-1399. [CrossRef]

18. Knudsen, J.N.; Jensen, P.A.; Lin, W.; Frandsen, F.J.; Dam-Johansen, K. Sulfur Transformations during Thermal Conversion of Herbaceous Biomass. Energy Fuels 2004, 18, 810-819. [CrossRef]

19. Du, S.; Yang, H.; Qian, K.; Wang, X.; Chen, H. Fusion and transformation properties of the inorganic components in biomass ash. Fuel 2014, 117, 1281-1287. [CrossRef]

20. Zheng, Y.; Pan, Z.; Zhang, R. Overview of biomass pretreatment for cellulosic ethanol production. Int. J. Agric. Biol. Eng. 2009, 2, 51-68. [CrossRef]

21. McKendry, P. Energy production from biomass (part 1): Overview of biomass. Bioresour Technol. 2002, 83, 37-46. [CrossRef]

22. Ragauskas, A.J.; Beckham, G.T.; Biddy, M.J.; Chandra, R.; Chen, F.; Davis, M.F.; Davison, B.H.; Dixon, R.A.; Gilna, P.; Keller, M.; et al. Lignin Valorization: Improving Lignin Processing in the Biorefinery. Science 2014, 344. [CrossRef] [PubMed]

23. Schmid, J.C.; Benedikt, F.; Fuchs, J.; Mauerhofer, A.M.; Müller, S.; Hofbauer, H. Syngas for biorefineries from thermochemical gasification of lignocellulosic fuels and residues -5 years' experience with an advanced dual fluidized bed gasifier design. Biomass Convers. Bioref. 2019. [CrossRef]

24. Benedikt, F.; Mauerhofer, A.M.; Fuchs, J.; Schmid, J.C. Gasification of Softwood and Lignin; Technical Report of Scientific Research; TU Wien: Vienna, Austria, 2018.

25. Bale, C.W.; Bélisle, E.; Chartrand, P.; Decterov, S.A.; Eriksson, G.; Gheribi, A.E.; Hack, K.; Jung, I.-H.; Kang, Y.-B.; Melançon, J.; et al. FactSage thermochemical software and databases, 2010-2016. Calphad 2016, 54, 35-53. [CrossRef] 
26. Hofbauer, H.; Rauch, R.; Bosch, K.; Koch, R.; Aichernig, C. Biomass CHP Plant Güssing-A Success Story; Bridgwater, A.V., Ed.; Pyrolysis and Gasification of Biomass and Waste; CPL Press: Newbury, UK, 2003; pp. 371-383.

27. Font Palma, C. Modelling of tar formation and evolution for biomass gasification: A review. Appl. Energy 2013, 111, 129-141. [CrossRef]

28. Yu, H.; Zhang, Z.; Li, Z.; Chen, D. Characteristics of tar formation during cellulose, hemicellulose and lignin gasification. Fuel 2014, 118, 250-256. [CrossRef]

29. Aigner, I.; Pfeifer, C.; Hofbauer, H. Co-gasification of coal and wood in a dual fluidized bed gasifier. Fuel 2011, 90, 2404-2412. [CrossRef]

30. CEN/TS 15439:2006. Biomass Gasification-Tar and Particles in Product Gases-Sampling and Analysis; European Committee for Standardization: Brussels, Belgium, 2006.

31. Chirone, R.; Salatino, P.; Scala, F.; Solimene, R.; Urciuolo, M. Fluidized bed combustion of pelletized biomass and waste-derived fuels. Combust. Flame 2008, 155, 21-36. [CrossRef]

32. Krishnarao, R.V.; Subrahmanyam, J.; Jagadish Kumar, T. Studies on the formation of black particles in rice husk silica ash. J. Eur. Ceram. Soc. 2001, 21, 99-104. [CrossRef]

33. Fuchs, J.; Müller, S.; Hofbauer, H. Ash Related Limitations of Dual Fluidized Bed Steam Gasification. In Proceedings of the 13th Minisymposium Chemical and Process Engineering, Innsbruck, Austria, 29-30 March 2017. Book of Abstracts.

34. Cui, H.; Ninomiya, Y.; Masui, M.; Mizukoshi, H.; Sakano, T.; Kanaoka, C. Fundamental Behaviors in Combustion of Raw Sewage Sludge. Energy Fuels 2006, 20, 77-83. [CrossRef]

35. Cammarota, A.; Chirone, R.; Salatino, P.; Scala, F.; Urciuolo, M. Attrition phenomena during fluidized bed combustion of granulated and mechanically dewatered sewage sludges. Proc. Combust. Inst. 2005, 30, 3017-3024. [CrossRef]

36. Canò, G.; Salatino, P.; Scala, F. A single particle model of the fluidized bed combustion of a char particle with a coherent ash skeleton: Application to granulated sewage sludge. Fuel Process. Technol. 2007, 88, 577-584. [CrossRef]

37. Troiano, M.; Cammarota, A.; Tregambi, C.; Chirone, R.; Salatino, P.; Solimene, R. Fluidized bed combustion of solid lignin-rich residues from bioethanol production. Powder Technol. 2020, 371, 170-179. [CrossRef]

38. Biswas, A.K.; Rudolfsson, M.; Broström, M.; Umeki, K. Effect of pelletizing conditions on combustion behaviour of single wood pellet. Appl. Energy 2014, 119, 79-84. [CrossRef]

39. Liakakou, E.T.; Vreugdenhil, B.J.; Cerone, N.; Zimbardi, F.; Pinto, F.; André, R.; Marques, P.; Mata, R.; Girio, F. Gasification of lignin-rich residues for the production of biofuels via syngas fermentation: Comparison of gasification technologies. Fuel 2019, 251, 580-592. [CrossRef]

40. Pagliari, L.; Dapiaggi, M.; Pavese, A.; Francescon, F. A kinetic study of the quartz-cristobalite phase transition. J. Eur. Ceram. Soc. 2013, 33, 3403-3410. [CrossRef]

41. Broekmans, M.A.T.M. The Alkali-Silica Reaction: Mineralogical and Geochemical Aspects of some Dutch Concretes and Norwegian Mylonites. Ph.D. Thesis, University of Utrecht, Utrecht, The Netherlands, 2002.

42. Heaney, P.J. Structure and chemistry of the low-pressure silica polymorphs. Rev. Mineral. Geochem. 1994, 29, 1-40.

43. Threlfall, T. Structural and Thermodynamic Explanations of Ostwald's Rule. Org. Process. Res. Dev. 2003, 7 , 1017-1027. [CrossRef]

44. Isaak, P.; Tran, H.; Barham, D.; Reeve, D.W. Stickiness of fireside deposits in kraft recovery unit. J. Pulp Pap. Sci. 1986, 12, 84-88.

45. Tran, H.N.; Mao, X.; Kuhn, D.C.S.; Backman, R.; Hupa, M. The Sticky Temperature of Recovery Boiler Fireside Deposits; Annex Publishing \& Printing, Inc.: Simcoe, ON, Canada, 2002.

46. Evic, N.; Brunner, T.; Obernberger, I. Prediction of Biomass Ash Melting Behaviour-Correlation between the Data Obtained from Thermodynamic Equilibrium Calculations and Simultaneous Thermal Analysis (STA). In Proceedings of the 20th European Biomass Conference and Exhibition, Milan, Italy, 18-22 June 2012.

(C) 2020 by the authors. Licensee MDPI, Basel, Switzerland. This article is an open access article distributed under the terms and conditions of the Creative Commons Attribution (CC BY) license (http://creativecommons.org/licenses/by/4.0/). 